\title{
Saliva as a non-invasive material for early diagnosis
}

\author{
Monika Woźniak $\bowtie$, Czesława Paluszkiewicz and Wojciech Maria Kwiatek \\ Institute of Nuclear Physics, Polish Academy of Sciences, Kraków, Poland
}

The proper diagnosis is a critical factor to reduce further disturbances at the early stage of the disease and plays an important role in increasing the success rate of the therapy. The traditional diagnostic tools such as biopsy or blood collection are always associated with patient's discomfort, the possibility of infections and time-consuming procedures. This article describes the non-invasive and easily accessible saliva as a source of numerous molecular biomarkers. The salivary fluid can provide information about the pathological changes not only in the oral area but also in other parts of the body, therefore salivary tests may be promising tools for risk prediction and treatment monitoring of many disorders.

Key words: saliva, biomarkers, diagnostic tool, salivary glands Received: 09 January, 2019; revised: 10 October, 2019; accepted: 07 November, 2019; available on-line: 04 December, 2019

凶e-mail: monika.wozniak@ifj.edu.pl

Abbreviations: Bax, Pro-apoptotic regulator gene; Bcl-2, B-cell lymphoma 2 gene; CRP, C-Reactive Protein; DNA, Deoxyribonucleic acid; ECG, electrocardiogram; EFIRM, Electric Field-Induced Release and Measurement; ELISA, Enzyme-Linked ImmunoSorbent Assay; EGFR, Epidermal Growth Factor Receptor; GFP, Green Fluorescent Protein; GLU, $\beta$-glucuronidase; HAV/HBV/HCV, Hepatitis A, B or C Virus; HEX, N-acetyl- $\beta$-d-hexosaminidase; HIV, Human Immunodeficiency Virus; HNSCC, Head and Neck Squamous Cell Carcinoma; IgA, IgG, IgM, IgG, Immunoglobulins $A, G, M$; RT PCR, Real-time Polymerase Chain Reaction; RNA, Ribonucleic acid

\section{INTRODUCTION}

Biofluids such as blood, urine, sweat, bile or cerebrospinal fluid may illustrate the condition of our body. These biological materials contain a number of relevant biomarkers such as proteins, lipids, carbohydrates or DNA fragments and provide important information about the physiological status of the organism, therefore they are widely used in medical diagnostics. In the recent several years, saliva, one of the bio liquids, has been highly appreciated as a useful tool in biomedical research. Saliva is one of the most important liquid factors responsible for maintaining homeostasis in the oral cavity. It is secreted by salivary glands and takes part in moisturizing of oral tissue, forming billets and digesting. Moreover, saliva allows to feel the flavour, protects the surface of the mucous membrane against the chemical agents and helps in the articulation of speech sounds. Some of the research demonstrated that the determination of salivary compounds may allow predicting the progression of many diseases (Pfaffe et al., 2011). Initially, saliva became an interesting biological material for medical research, because of many dental studies which indicated the usefulness of this body fluid in oral diseases such as bacterial caries, dental tartar or fungal infections (Gao et al., 2016).
Nowadays, the saliva-based tests may become equally valuable tools in the diagnosis of many serious diseases as the blood tests. The increasing popularity of the salivary tests is related to the several advantages of this biological material, such as availability, facility, low cost of collection, non-invasive and painless method of collection. Moreover, the compounds present in the saliva are characterized by high stability (Kaufman \& Lamster, 2002). The composition of saliva depends on the current physiological state of the body, hence it may provide many relevant information about the cause of the disease. many diagnostic opportunities to discover the cause of diseases (Cyprysiak \& Tadeusiak, 2008). What is more, a medical treatment very often requires multiple sample collections, but the patients are exposed to discomfort related to invasive and stressful blood or tissue collection and resign from the further monitoring of treatment. That is why, the non-invasive salivary fluid collection seems to be a good alternative to the traditional methods of diagnosis (Segal \& Wong, 2008). The main goal of the current molecular biology research is to identify a set of proteins present in saliva to determine the salivary biomarkers of diseases. Then the salivary testing may be an alternative to more expensive and invasive diagnostic procedures.

\section{SECRETION}

The production of saliva is controlled by the autonomic nervous system and the main secretion occurs in the parotid, submandibular and sublingual salivary glands (Fig. 1). Additionally, the smaller part of saliva is also secreted by small salivary glands located in the palate and tongue. The $75 \%$ of the total secretion comes from the submandibular gland and it is stimulated by both sympathetic and parasympathetic nervous systems. Usually, the saliva production starts with unconditional reflex through

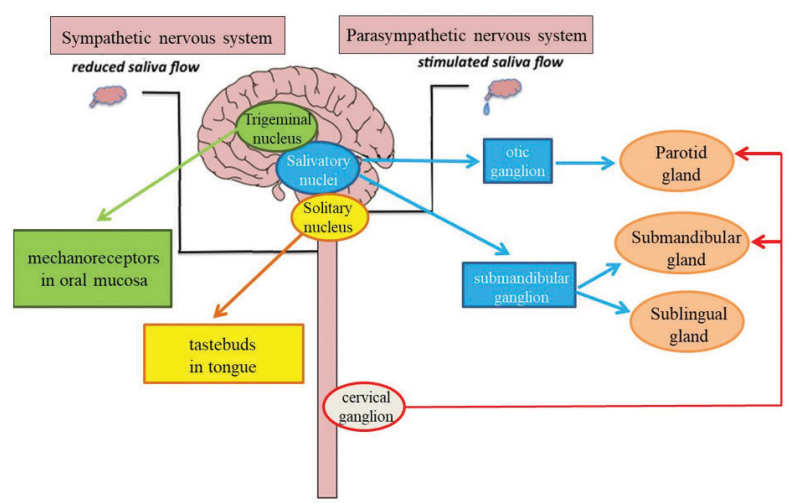

Figure 1. Scheme of the saliva secretion controlled by sympathetic and parasympathetic nervous systems 
irritation of the taste receptors after getting food, but it may also be affected by visual, olfactory and psychological stimuli and the hormonal system (Paszyńska, 2005). The sympathetic nervous system is responsible for releasing norepinephrine which binds to $\alpha$-adrenergic receptors and as a result, it increases the intracellular calcium level. The abovementioned process is responsible for the formation of the thick saliva fraction. Due to the presence of non-enzymatic proteins - mucins - saliva becomes thicker. The general role of thick saliva is moisturizing the mucous membranes and preventing the dehydration. And in this way, the saliva produced by the sympathetic system supports the respiratory functions. In contrast, the parasympathetic nervous system releases the acetylcholine which binds to muscarinic receptors and causes an increased intracellular calcium level. It results in a higher content of inorganic components in the saliva. For this reason, the parasympathetic secretion of saliva plays an important role in its digestive functions. The average production of saliva is between 0.5 to 1.5 litre per day (Pfaffe et al., 2011) and depends on the variation between individuals, however, it always decreases during sleep down to $2-10 \%$ of the daily amount (Cyprysiak \& Tadeusiak, 2008).

\section{COMPOSITION}

The main component of the saliva is water (94-99\%), but it also contains many important substances including organic and inorganic compounds. The concentration of specific compounds is responsible for the chemical and physical properties of the salivary fluid. The $\mathrm{pH}$ of fresh saliva is about 6.5 (Szydlarska et al., 2008). The saliva contains the inorganic part of cations such as $\mathrm{Na}^{+}, \mathrm{K}^{+}$, $\mathrm{Mg}^{2+}, \mathrm{Ca}^{2+}$ and anions $\mathrm{Cl}^{-}, \mathrm{F}^{-}, \mathrm{I}^{-}$(Zhang et al., 2016). The abovementioned ions take part in the transport of active compounds through the cellular membranes in or out the cell, the formation of dental structures and activation of some enzymes, such as hydrolases, phosphatases, dehydrogenases or peroxidases. Moreover, fluorine plays an important role in the remineralization of enamel and protection against oral bacteria. The organic part of saliva includes 0.5 to $3 \mathrm{mg} / \mathrm{mL}$ proteins, carbohydrates, lipids, urea and hormones (Tibor et al., 2007). The most significant salivary proteins are mucins. These glycoproteins which constitute $20-30 \%$ of total proteins in saliva of total proteins are responsible for the viscosity and density of saliva. The main function of glycoproteins is ensuring lubricity and playing a role in the teeth mineralization process. What is more, glycoproteins contained in the body fluids may reflect the changes in the health condition. For example, blood as the main body fluid includes many agents such as the clotting factor which influences the blood coagulation process. Similarly, many factors present in saliva may play important functions in the organism as well, but with the difference that the salivary material collection is much faster and more convenient. What is more, some research already confirmed the usefulness of salivary material for exoglycosidases determination, such as HEX ( $\mathrm{N}$-acetyl- $\beta$-D-hexosaminidase) or GLU ( $\beta$-glucuronidase), which may be the basis for clinical diagnosis (Chojnowska et al., 2014). Furthermore, the mentioned glycoproteins take part in immune system protection by binding to the pathogens. The latest research indicates that overexpression of mucins in the oral cavity is associated with many types of cancer ( $\mathrm{Hu}$ et al., 2008; Kaczor-Urbanowicz et al., 2017). The remaining proteins found in saliva are cystatins and immunoglobu-

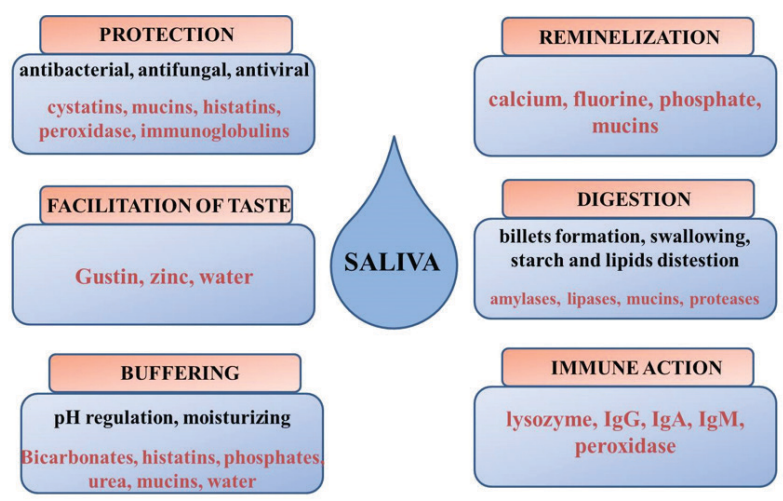

Figure 2. Selected major functions of saliva

lins which actively participate in inflammatory processes and bacteria elimination whereas lysozyme and $\alpha$-amylase are involved in digestion. In addition to proteins, saliva contains also lipid components $(10-100 \mu \mathrm{g} / \mathrm{mL})$ which may play an important role in the dental plaque and caries formation (Larsson et al., 1996). Finally, molecules such as DNA or RNA present in the blood and tissues can also be found in the saliva (Wang et al., 2017).

\section{FUNCTIONS}

The main role of the saliva is a protective and digestive function. With its $\mathrm{pH}$ close to neutral, it plays a role as a buffer which moistens the nourishment and supports swallowing to the further parts of the digestive system (Pink et al., 2009). In addition, saliva removes harmful metabolism products from the teeth surface and protects them from bacteria. The clearance action is performed through the following saliva components: phosphate, bicarbonate, urea and enzymes (Humphrey \& Williamson, 2001). The cystatins present in the saliva alleviate the inflammation process, while mucins protect the mucous membrane against toxins from the food. Although the structure of the saliva oligosaccharides is well-known, there is no data, which show the relationship between structure and biological function of salivary mucins (Zalewska et al., 2000). Moreover, the moisturizing function prevents dehydration and premature cell death. The presence of magnesium and calcium ions facilitates wound healing and inhibits demineralization. The salivary fluid uses two mechanisms of protection against infections. One of them is based on non-specific antibacterial and antifungal factors such as salivary peroxidase, histatin or lysozyme. On the other hand, saliva uses specific immune factors, means immunoglobulins such as $\operatorname{IgA}$, IgM, IgG which are responsible for phagocytosis. Beside, saliva contains a number of antioxidants that delay cellular oxidation. Due to the rich composition, saliva is functionally equivalent to blood in reflecting the physiological state of the body, thus it may inform about hormonal, nutritional and immune functions of the organism (Lee \& Wong, 2009). All of the mentioned functions are summarized in Fig. 2.

\section{SALIVA IN MEDICAL DIAGNOSIS}

The availability of saliva and non-invasive method of its collection are very important advantages of diagnostic biological material. Easy storage and long-term stability are the next benefits of this biofluid. The richness of the 
Table 1. The advantages and disadvantages of salivary fluid used for medical diagnosis

\begin{tabular}{lc}
\hline Advantages & Disadvantages \\
\hline $\begin{array}{l}\text { long-term stability } \\
\text { high availability }\end{array}$ & $\begin{array}{c}\text { still low standardization } \\
\text { lower level of biomarkers } \\
\text { safe (non-infectious) }\end{array}$ \\
$\begin{array}{l}\text { easy process of analysis } \\
\text { wide range of biomarkers }\end{array}$ & $\begin{array}{c}\text { risk of altering the results } \\
\text { by oral inflammation }\end{array}$ \\
$\begin{array}{l}\text { fast and simple collection } \\
\text { (non-invasive) }\end{array}$ & \\
home testing (no stress, & \\
no pain) & \\
cost-effective (no specialized & \\
equipment) &
\end{tabular}

contained compounds allows performing a wide range of tests. Moreover, the collection of this biofluid is comfortable and painless for the patients and the cost of the procedure is relatively low, therefore saliva can be one of the best materials for the medical diagnosis (Szydlarska et al., 2008; Yoshizawa et al., 2013).

Initially, saliva composition played an important role only in dentistry. It was the source of information about periodontal diseases, for example caries formation, scale or inflammation of the oral cavity (Gao et al., 2016). Salivary tests allow not only to obtain a full picture of oral cavity condition but also to determine the concentration of various important compounds which reflect the whole body health's state. A lot of important factors responsible for genetic diseases are located in deoxyribonucleic acid. The DNA isolated from saliva can tolerate storage at room temperature for up to 5 days, therefore salivary fluid is an adequate biological material for genetic analysis (Nemoda et al., 2011). Due to the aforementioned advantages, saliva seems to have a wide application in medicine. Unfortunately, like every biological material it has also weaknesses (see below in Table 1). Firstly, saliva does not contain all the biomarkers which occur in the other parts of the body such as tissues or blood and sometimes the poor standardization does not allow the proper interpretation of the obtained results. Secondly, in the case of salivary samples, there is a risk of biasing the results by oral cavity infections.

\section{GASTROLOGY}

The salivary fluid is a very useful tool in digestive disturbances. The acidic $\mathrm{pH}$ and decreased concentration of $\mathrm{Na}^{+}$ions in saliva may increase the risk of occurrence of gastro-oesophageal reflux (Bouchoucha et al., 1997), therefore monitoring of saliva $\mathrm{pH}$ is an important factor in controlling the condition of the oesophagus. One of the causes of digestive system diseases is the presence of Helicobacter pylori. These small bacteria are responsible for peptic ulcers and gastritis. The H. pylori infection correlates with a high level of immunoglobulins such as $\operatorname{IgG}$ which can be measured in the salivary fluid. Furthermore, the DNA of Helicobacter pylori and other gastrointestinal bacteria can be detected in saliva using PCR (Polymerase Chain Reaction) or ELISA (Enzyme-Linked ImmunoSorbent Assay) with 85\% sensitivity (Loeb et al., 1997).

\section{ENDOCRINOLOGY}

Endocrinology is one of the fields which widely use salivary-based diagnostic tests. The level of hormones has daily and cyclic fluctuations, thus the methods which allow multiple and non-invasive collection of biomaterial are very important. The salivary fluid can provide the information about the level of major hormones such as cortisol (stress hormone) (Lambert et al., 2018), progesterone involved in pregnancy or estrogen and testosterone which play a key role in the development of respectively: female or male reproductive cells and promote secondary sexual characteristics. The prolonged exposure to cortisol is connected with several stress-related diseases, for example Cushing's syndrome manifested by an excessive weight gain or neurosis. Both disorders are asymptomatic at the beginning, that is why the monitoring of cortisol levels is very important (Sakihara et al., 2010). The level of steroid hormones such as testosterone is used to study sexual dysfunctions, libido, puberty, hirsutism or tendency to aggression. Moreover, in patients with diabetes a reduced secretion of saliva and increased level of antioxidants such as dismutase and peroxidase were observed (Reznick et al., 2006). What is more, another group of researchers (Knas et al., 2006) found a reduced concentration of several enzymes (such as $N$-acetyl- $\beta$-hexosaminidase) in the saliva of patients with diabetes.

\section{PHARMACOLOGY}

Moreover, saliva is an important material in toxicology tests, because it may provide information about the consumed drugs (Drobitch \& Svensson, 1992) and levels of metals such as lithium or cadmium, therefore, it is a useful tool in planning and monitoring of medicines pharmacokinetics. Very often it is used to check the presence of addictive and psychoactive chemicals such as alcohol, amphetamine, cocaine, marijuana or barbiturates. The presence of the mentioned substances is detected in saliva for up to 12-24 hours and the concentration of amphetamine in saliva corresponds to the serum concentration (Pink et al., 2009).

\section{VIROLOGY/BACTERIOLOGY}

The salivary tests play an important role in the virology. In contrast to blood, saliva is a non-infectious fluid, therefore it can be a useful material for detection of RNA/DNA of viruses, for example HIV virus (Human Immunodeficiency Virus) (Scully et al., 1997), $\mathrm{HAV} / \mathrm{HBV} / \mathrm{HCV}$ (Hepatitis A, B or C Virus) (Mackiewicz et al., 2004), measles (Paramyxovirus) or rubella (Rubivirus). The presence of antibodies against pathogens in the saliva can be investigated by molecular biology methods such as Real-time PCR, Western-blot or ELISA technique. These methods use a comparative analysis between control and tested samples based on proteins and genetic material contained in saliva. The sensitivity and specificity of the abovementioned methods in saliva tests are around 95-99\%, therefore it seems that saliva is a stable and suitable material for pathogenic analysis (Mackiewicz et al., 2004). The polymerase chain reaction on the salivary fluid is commonly used to detect also other diseases of parasitic or bacterial aetiology, such as malaria (Plasmodium vivax) (Buppan et al., 2010) or mentioned previously gastritis and gastric ulcers (caused by Helicobacter pylori) (Loeb et al., 1997). 


\section{CARDIOLOGY}

The salivary fluid is also a very useful tool in diagnosing cardiovascular disturbances. CRP (C-Reactive Protein) plays a significant role in an acute inflammatory state and it is one of the myocardial infarction factors. The myeloperoxidase and myoglobin are also used as the heart diseases markers. These indicators take part in the initiation of cardiovascular changes and their level in saliva is correlated with similar detection in blood (Ganowicz, 2011). The salivary test can eliminate the need of using an ECG which detects only about $35 \%$ of acute myocardial infractions (Yeh et al., 2010). One of the modern techniques for analysing biomarkers from liquid biological material is Nano-Biochip. This technology allows analysing the relevant factors affecting myocardial dysfunctions such as proteins, antibodies, electrolytes or toxins (Floriano et al., 2009; Miller et al., 2010).

\section{IMMUNOLOGY}

Another disease associated with salivary flow disorders is Sjögren's syndrome. It is an autoimmune disease connected with salivary gland damage and dryness of mucous membranes. The amount and composition of saliva are strongly associated with Sjögren's syndrome symptoms. For example, the saliva of patients with the mentioned disorder contains a much higher total concentration of proteins when compared to the control group (Ganowicz, 2011). Furthermore, the dysregulation of pro- and anti-apoptotic proteins expression such as Bax and Bcl-2 was noticed in Sjögren's patients (Ohlsson et al., 2002). Another group of scientists identified more than 40 saliva proteins involved in Sjögren's syndrome using mass spectrometry and expression microarray. Hu et al. found 16 proteins, such as carbonic anhydrase VI, lysozyme C or cystatins, which were down-regulated in patients with Sjögren's syndrome in comparison to the healthy controls. In the same study, other 25 proteins, such as haemoglobin $\beta$-chain, salivary $\alpha$-amylase or caspase 14 were overexpressed in Sjögren's group and, what is more, the levels of these proteins reflected oral cavity inflammation and glandular cells damage ( $\mathrm{Hu}$ et al., 2007).

\section{NEUROLOGY}

Interestingly, the diagnostic potential of saliva is also used in mental disorders. For instance, $\beta$-amyloid accumulated in the brain and responsible for Alzheimer's disease symptoms is also found in the saliva solution. The traditional diagnosis of Alzheimer's disease is very difficult and time-consuming because it involves psychological tests, brain imaging and needs to differentiate the disease from the other neurodegenerative diseases. For this reason, the salivary tests seem to be a good and rapid method for early diagnosis of amyloid level changes. Some researchers indicated that salivary lactoferrin may also be a putative marker for early diagnosis of Alzheimer's disease (Carro et al., 2017). Moreover, cortisol which was mentioned earlier is also a commonly applied marker in the studies of depression, anxiety and other stress disorders. This steroid hormone and the salivary $\alpha$-amylase are two of the most useful markers in the stress research. Both are used as the sympathetic nervous system activity markers and the procedure does not require a blood collection (Noto et al., 2005; Granger et al., 2007; Nater \& Rohleder, 2009). Similarly, the testos- terone concentration is also used in the studies on the tendency to aggression and addiction. Another example of the central nervous system disorder is alcohol addiction. In alcohol-dependent patients, a significant decrease of salivary flow and lactoferrin level in the saliva was noticed when compared to the control group, which may be useful as the marker of alcohol addiction (Waszkiewicz et al., 2012).

\section{ONCOLOGY}

Detection of the majority of cancer changes is mainly based on invasive tissue biopsy. Despite therapeutic advances, the overall survival rate remains low, because the traditional diagnosis such as histopathological examination usually occurs at advanced stages and that is why the prognosis for further treatment is very poor. Most of all, head and neck squamous cell carcinoma (HNSCC) is difficult to diagnose due to its inconvenient location. Therefore, the body fluids, such as saliva may be an important material for monitoring of oral tumours (Zimmermann, 2008; Yakob et al., 2014; Liu et al., 2016). Moreover, a biopsy is a quite expensive, unpleasant and time-consuming method, therefore scientists try to find an alternative way to analyse the genetic markers of tumours. One of the novel technology which is called EFIRM (Electric Field-Induced Release and Measurement) can monitor RNA/DNA and protein biomarkers in the body fluids and eliminates the biopsy procedure. The usefulness of biological fluids was confirmed in human lung cancer studies where the tumour-shed hCD63GFP exosomes were detected in blood and saliva (Wei et al., 2013). The same group of researchers showed in 2014 that another biomarker, EGFR (Epidermal Growth Factor Receptor) which plays an important role in the signalling pathway of carcinogenesis, may be directly detected in salivary fluid and provide the information about EGFR mutation (Wei et al., 2014). Recent studies demonstrated the presence of breast, ovarian and pancreatic cancer biomarkers in the saliva as well (Zhang et al., 2010; Lau et al., 2013).

\section{CONCLUDING REMARKS AND FUTURE PERSPECTIVES}

The advanced research confirmed that saliva is a significant biological material for many diagnostic tests. The

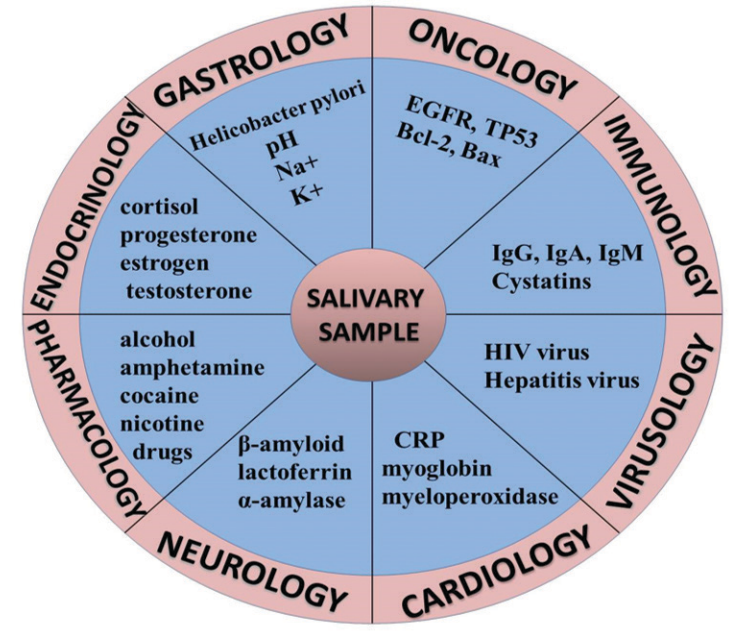

Figure 3. Examples of selected salivary biomarkers in various of medicine fields 
most important advantages of saliva as a diagnostic material is the non-invasive, non-expensive and non-timeconsuming method of collection. Despite many important advantages, saliva has some drawbacks as every material (see Table 1). Unfortunately, not all markers occur in saliva, and in some cases, such as periodontitis, the concentration of tested factors can be slightly changed. However, it does not change the fact that saliva contains a number of important biomarkers (Fig. 3). Apart from the exceptional instances, mentioned advantages of variety tests and methods using saliva (such as RT-PCR, ELISA, Western-blot, EFIRM, Raman spectroscopy) determine that salivary fluid is a flexible and very useful tool in numerous of biomedical studies. Moreover, exploring the molecular biomarkers contained in the saliva is promising for early diagnosis, risk prediction and treatment monitoring in many disorders, also in some of still incurable world's diseases.

Considering the efficacy and cost-effectiveness of salivary-based procedures, it seems that saliva may be a very useful material in biomedical diagnosis as confirmed by preliminary and some clinical studies. The most important advantage of salivary fluid is its potential for screening for multiple diseases. However, due to the inadequate procedures for standardization of the results, much more work needs to be done to implement the salivary diagnostic tests into daily use. Firstly, the salivary biomarkers should be precisely clarified in order to connect them with the appropriate disease. Secondly, the validation and standardization of saliva should be unified as in the case of the other bio fluids. Furthermore, easyto-use home testing devices should be developed to promote self-examination of patients. Taking into account all pros and cons, and assuming that some shortcomings need to be overcome, the salivary-based diagnosis may be one of the best tools for early prediction of many diseases in the near future.

\section{REFERENCES}

Bouchoucha M, Callais F, Renard P, Ekindjian OG, Cugnenc PH, Barbier JP (1997) Relationship between acid neutralization capacity of saliva and gastro-oesophageal reflux. Arch. Physiol. Biochem. 105: 19-26. https://doi.org/10.1076/apab.105.1.19.13152

Buppan P, Putaporntip C, Pattanawong U, Seethamchai S, Jongwutiwes S (2010) Comparative detection of Plasmodium vivax and Plasmodium falciparum DNA in saliva and urine samples from symptomatic malaria patients in a low endemic area. Malar. J. 9: 72. https://doi, org/10.1186/1475-2875-9-72

Carro E, Bartolomé F, Bermejo-Pareja F, Villarejo-Galende A, Molina JA, Ortiz P, Calero M, Rabano A, Cantero JL, Orive G (2017) Early diagnosis of mild cognitive impairment and Alzheimer's disease based on salivary lactoferrin. Alsheimer's Dement. Diagnosis, Assess. Dis. Monit. 8: 131-138. https://doi.org/10.1016/j.dadm.2017.04.002

Chojnowska S, Baran T, Wilińska I, Sienicka P, Cabaj-Wiater I, Knaś M (2014) Determination of lysosomal exoglycosidases in human saliva, Acta Biochim. Pol. 61: 85-90. doi: 10.1016/j.advms.2017.11.002

Cyprysiak G., Tadeusiak W (2008) Application of saliva in medicine. Nowa Stomatologia. 33-36 (in Polish)

Drobitch RK., Svensson CK (1992) Therapeutic drug monitoring in saliva. Clin. Pharmacokinet. 23: 365-379. https://doi, org/10.2165/00003088-199223050-00003.

Floriano PN, Christodoulides N, Miller CS, Ebersole JL, Spertus J, Rose BG, Kinane DF, Novak MJ, Steinhubl S, Acosta S, Mohanty S, Dharshan P, Yeh CK, Redding S, Furmaga W, McDevitt JT (2009) Use of saliva-based nano-biochip tests for acute myocardial infarction at the point of care: a feasibility study. Clin. Chem. 55: 1530-1538. https://doi.org/10.1373/clinchem.2008.117713

Ganowicz E (2011) Application of saliva in medicine. Dent. Med. Probl. 48: 554-561 (in Polish)

Gao X, Jiang S, Koh D, Hsu CY (2016) Salivary biomarkers for dental caries. Periodontol. 2000. 70: 128-141. https://doi.org/10.1111/ prd. 12100

Granger DA, Kivlighan KT, el-Sheikh M, Gordis EB, Stroud LR (2007) Salivy $\alpha$-amylase in biobehavioral research: Recent develop- ments and applications. Ann. N. Y. Acad. Sci. 1098: 122-144. https://doi.org/10.1196/annals.1384.008

$\mathrm{Hu}$ S. et al. (2007) Salivary proteomic and genomic biomarkers for primary Sjögren's syndrome. Arthritis Rheum. 56: 3588-3600. https:// doi.org/10.1002/art.22954

Hu S, Wang J, Meijer J, Ieong S, Xie Y, Yu T, Zhou H, Henry S, Vissink A, Pijpe J, Kallenberg C, Elashoff D, Loo JA, Wong DT (2008) Salivary proteomics for oral cancer biomarker discovery. Clin. Cancer Res. 14: 6246-6252. https://doi.org/10.1158/1078-0432. CCR-07-5037

Humphrey SP, Williamson RT (2001) A review of saliva: Normal composition, flow, and function. J. Prosthet. Dent. 85: 162-169. https:// doi.org/10.1067/mpr.2001.113778

Kaczor-Urbanowicz KE, Martin Carreras-Presas C, Aro K, Tu M, Garcia-Godoy F, Wong DT (2017) Saliva diagnostics - Current views and directions. Exp. Biol. Med. 242: 459-472. https://doi. org/10.1177/1535370216681550

Kaufman E, Lamster IB (2002) The diagnostic applications of saliva - A review. Crit. Rev. Oral Biol. Med. 13: 197-212. https://doi. org/10.1177/154411130201300209

Karaszewska K, Szajda SD, Zarzycki W, Dudzik D, Zwierz K (2006) Saliva of patients with Type 1 diabetes: effect of smoking on activity of lysosomal exoglycosidases. Oral Dis. 12: 278-282. https://doi. org/org/10.1111/j.1601-0825.2005.01190.x

Couture-Lalande ME, Brennan K, Basic A, Lebel S, Bielajew C (2018) Salivary secretory immunoglobulin A reactivity: a comparison to cortisol and $\alpha$-amylase patterns in the same breast cancer survivors. Contemp Oncol. 22: 191-201. https://doi.org/10.5114/wo.2018.78946

Larsson B, Olivecrona G, Ericson T (1996) Lipids in human saliva. Arch. Oral Biol. 41: 105-110. https://doi.org/10.1016/00039969(95)00077-1

Lau C, Kim Y, Chia D, Spielmann N, Eibl G, Elashoff D, Wei F, Lin YL, Moro A, Grogan T, Chiang S, Feinstein E, Schafer C, Farrell J, Wong DT (2013) Role of pancreatic cancer-derived exosomes in salivary biomarker development. J. Biol. Chem. 288: 26888-26897. https://doi.org/10.1074/jbc.M113.452458

Lee YH, Wong DT (2009) Saliva: An emerging biofluid for early detection of diseases. Am. J. Dent. 22: 241-248

Liu D, Zhao X, Zeng X, Dan H, Chen Q (2016) Non-invasive techniques for detection and diagnosis of oral potentially malignant disorders. Tohoku J. Exp. Med. 238: 165-177. https://doi.org/10.1620/ tjem.238.165

Loeb MB, Riddell RH, James C, Hunt R, Smaill FM (1997) Evaluation of salivary antibodies to detect infection with Helicobacter pylori. Can. J. Gastroenterol. 11: 437-440. https://doi.org/10.1155/1997/294081

Mackiewicz V1, Dussaix E, Le Petitcorps MF, Roque-Afonso AM (2004) Detection of hepatitis A virus RNA in saliva. J. Clin. Microbiol. 42: 4329-4331. https://doi.org/10.1128/JCM.42.9.43294331.2004

Miller CS, Foley JD, Bailey AL, Campell CL, Humphries RL, Christodoulides N, Floriano PN, Simmons G, Bhagwandin B, Jacobson JW, Redding SW, Ebersole JL, McDevitt JT (2010) Current developments in salivary diagnostics. Biomark. Med. 4: 171-189. https:// doi.org/10.2217/bmm.09.68

Nater UM, Rohleder N (2009) Salivary alpha-amylase as a noninvasive biomarker for the sympathetic nervous system: current state of research. Psychoneuroendocrinology 34: 486-496. https://doi. org/10.1016/j.psyneuen.2009.01.014

Nemoda Z, Horvat-Gordon M, Fortunato CK, Beltzer EK, Scholl JL, Granger DA (2011) Assessing genetic polymorphisms using DNA extracted from cells present in saliva samples. BMC Med. Res. Methodol. 11: 170. https://doi.org/10.1186/1471-2288-11-170

Noto Y, Sato T, Kudo M, Kurata K, Hirota K (2005) The relationship between salivary biomarkers and state-trait anxiety inventory score under mental arithmetic stress: a pilot study. Anesth. Analg. https:// doi.org/10.1213/01.ANE.0000184196.60838.8D

Ohlsson M, Szodoray P, Loro LL, Johannessen AC, Jonsson R (2002) CD40, CD154, Bax and Bcl-2 Expression in Sjogren's syndrome salivary glands: a putative anti-apoptotic role during its effector phases. Scand. J. Immunol. 56: 561-571. https://doi.org/10.1046/ j.1365-3083.2002.01168.x

Paszyńska E (2005) Selected factors affecting salivation and composition. Dental forum, XXXII, 86-90 (in Polish)

Pfaffe T, Cooper-White J, Beyerlein P, Kostner K, Punyadeera C (2011) Diagnostic potential of saliva: current state and future applications. Clin. Chem. 57: 675-87. https://doi.org/10.1373/ clinchem.2010.153767

Pink R. et al. (2009) Saliva as diagnostic medium. Biomed Pap Med Fac Univ Palacky Olomouc Czech Repub 153: 103-110. https://doi. org/10.5507/bp.2009.017

Reznick AZ, Shehadeh N, Shafir Y, Nagler RM (2006) Free radicals related effects and antioxidants in saliva and serum of adolescents with Type 1 diabetes mellitus. Arch. Oral Biol. 51: 640-648. https:// doi.org/10.1016/j.archoralbio.2006.02.004

Sakihara S, Kageyama K, Oki Y, Doi M, Iwasaki Y, Takayasu S, Moriyama T, Terui K, Nigawara T, Hirata Y, Hashimoto K, Suda T 
(2010) Evaluation of plasma, salivary, and urinary cortisol levels for diagnosis of Cushing?s syndrome. Endocr. J. 57: 331-337. https:// doi.org/10.1507/endocrj.k09e-340

Scully C (1997) HIV topic update: salivary testing for antibodies. Oral Dis. 3: 212-215. https://doi.org/10.1111/j.1601-0825.1997. tb00043.x

Segal A, Wong DT (2008) Salivary diagnostics: enhancing disease detection and making medicine better. Eur. J. Dent. Educ. 12: 22-29. https://doi.org/10.1111/j.1600-0579.2007.00477.x

Szydlarska D, Grzesiuk W, Kupstas A, Bar-Andziak E (2008) Saliva as a diagnostic material. Wybrane Probl. Klin. 454-464 (in Polish)

Fábián TK, Fejérdy P, Csermely P (2007) Saliva in Health and Disease, Chemical Biology of. Wiley Encycl. Chem. Biol. https://doi. org/10.1002/9780470048672.wecb643

Wang X, Kaczor-Urbanowicz KE, Wong DT (2017) Salivary biomarkers in cancer detection. Med. Oncol. 34: 7. https://doi.org/10.1007/ s12032-016-0863-4

Waszkiewicz N, Zalewska-Szajda B, Zalewska A, Waszkiewicz M, Szajda SD, Repka B, Szulc A, Kępka A, Minarowska A, Chojnowska S, Konarzewska B, Ladny JR, Kowzan U, Zwierz K (2012) Decrease in salivary lactoferrin output in chronically intoxicated alcohol-dependent patients. Folia Histochem. Cytobiol. 50: 248-254. https://doi. org/10.5603/fhc. 2012.0024

Wei F, Yang J, Wong DT (2013) Detection of exosomal biomarker by electric field-induced release and measurement (EFIRM). Biosens. Bioelectron. 44: 115-121. https://doi.org/10.1016/j.bios.2012.12.046

Wei F, Lin CC, Joon A, Feng Z, Troche G, Lira ME, Chia D, Mao M, Ho CL, Su WC, Wong DT (2014) Noninvasive saliva-based
EGFR gene mutation detection in patients with lung cancer. Am. J. Respir. Crit. Care Med. 190: 1117-1126. https://doi.org/10.1164/ rccm.201406-1003OC

Yakob M, Fuentes L, Wang MB, Abemayor E, Wong DT (2014) Salivary biomarkers for detection of oral squamous cell carcinomacurrent state and recent advances. Curr. Oral Heal. Rep. 1: 133-141. https://doi.org/10.1007/s40496-014-0014-y

Yeh CK, Christodoulides NJ, Floriano PN, Miller CS, Ebersole JL, Weigum SE, McDevitt J, Redding SW (2010) Current development of saliva/oral fluid-based diagnostics. Tex. Dent. J. 127: 651-661. PMCID: PMC3742318

Yoshizawa JM, Schafer CA, Schafer JJ, Farrell JJ, Paster BJ, Wong DT (2013) Salivary biomarkers: toward future clinical and diagnostic utilities. Clin. Microbiol. Rev. 26: 781-91. https://doi.org/10.1128/ CMR.00021-13

Zalewska A, Zwierz K, Zółkowski K, Gindzieński A (2000) Structure and biosynthesis of human salivary mucins. Acta Biochim. Pol. 47: 1067-1079. PMID: 11996097

Zhang L, Farrell JJ, Zhou H, Elashoff D, Akin D, Park NH, Chia D, Wong DT (2010) Salivary transcriptomic biomarkers for detection of resectable pancreatic cancer. Gastroenterology 138: 949-957. https://doi.org/10.1053/j.gastro.2009.11.010

Zhang CZ, Cheng XQ, Li JY, Zhang P, Yi P, Xu X, Zhou XD (2016) Saliva in the diagnosis of diseases. Int. J. Oral Sci. 8: 133-137. https://doi.org/10.1038/ijos.2016.38

Zimmermann BG, Wong DT (2008) Salivary mRNA targets for cancer diagnostics. Oral Oncol. 44: 425-429. https://doi.org/10.1016/j.oraloncology.2007.09.009 